\title{
Application of an artificial neural network model for diagnosing type 2 diabetes mellitus and determining the relative importance of risk factors
}

\author{
Shiva Borzouei', Ali Reza Soltanian²,3 \\ ${ }^{1}$ Department of Endocrinology, School of Medicine, Hamadan University of Medical Sciences, Hamadan, Iran; ${ }^{2}$ Department of Biostatistics, \\ School of Public Health, Hamadan University of Medical Sciences, Hamadan, Iran; ${ }^{3}$ Modeling of Noncommunicable Diseases Research Center, \\ School of Public Health, Hamadan University of Medical Sciences, Hamadan, Iran
}

OBJECTIVES: To identify the most important demographic risk factors for a diagnosis of type 2 diabetes mellitus (T2DM) using a neural network model.

METHODS: This study was conducted on a sample of 234 individuals, in whom T2DM was diagnosed using hemoglobin A1c levels. A multilayer perceptron artificial neural network was used to identify demographic risk factors for T2DM and their importance. The DeLong method was used to compare the models by fitting in sequential steps.

RESULTS: Variables found to be significant at a level of $\mathrm{p}<0.2$ in a univariate logistic regression analysis (age, hypertension, waist circumference, body mass index [BMI], sedentary lifestyle, smoking, vegetable consumption, family history of T2DM, stress, walking, fruit consumption, and sex) were entered into the model. After 7 stages of neural network modeling, only waist circumference (100.0\%), age (78.5\%), BMI (78.2\%), hypertension (69.4\%), stress (54.2\%), smoking (49.3\%), and a family history of T2DM (37.2\%) were identified as predictors of the diagnosis of T2DM.

CONCLUSIONS: In this study, waist circumference and age were the most important predictors of T2DM. Due to the sensitivity, specificity, and accuracy of the final model, it is suggested that these variables should be used for T2DM risk assessment in screening tests.

KEY WORDS: Statistical model, Glycated hemoglobin A, Epidemiology, Iran

\section{INTRODUCTION}

Type 2 diabetes mellitus (T2DM) is a non-contagious and chronic disease [1]. T2DM can cause many other diseases, such as cardi-

\section{Correspondence: Ali Reza Soltanian}

Department of Biostatistics, School of Public Health, Hamadan University of Medical Sciences, Ghaem, Lona Park, Hamadan 6517838736, Iran

E-mail:soltanian@umsha.ac.ir

Received: Feb 4, 2018 / Accepted: Mar 10, 2018 / Published: Mar 10, 2018

This article is available from: http://e-epih.org/

(C) This is an open-access article distributed under the terms of the Creative Commons Attribution License (http://creativecommons.org/licenses/by/4.0/), which permits unrestricted use, distribution, and reproduction in any medium, provided the original work is properly cited.

(C) 2018, Korean Society of Epidemiology ovascular disease [2], stroke [3], blindness [4], and loss of renal function [5].

The prevalence of diabetes is increasing. Worldwide, 285 million people had diabetes in 2010, compared to 422 million in 2014 [6] and this number is projected to increase to 438 million in 2030 [7] and 592 million in 2035 [8]. The prevalence of diabetes in lowincome or moderate-income countries is higher than in high-income countries [7], and it accounts for a large share of the mortality and disability rate in such communities [6]. One of the reasons for the high prevalence of diabetes in low-income countries may be low levels of knowledge and awareness about diabetes [9].

In 2010 and 2012, the number of undiagnosed cases of diabetes was reported to be 7 and 1.8 million, respectively, corresponding to approximately a quarter of the diagnosed cases [8]; it is also important to note that the cost of treating diabetes is greater than that of prevention. 
Therefore, the prevention of diabetes mellitus is of high importance in all communities. The first step in the prevention of T2DM is to identify its risk factors. Our literature review showed that factors such as age $[10,11]$, sex $[10,12]$, family history of diabetes [11, 13], hypertension [14], obesity [10,15], abdominal obesity [16], stress in the workplace or home $[17,18]$, a sedentary lifestyle $[19,20]$, smoking [21], insufficient fruit and vegetable consumption [22], and physical activity $[23,24]$ are risk factors associated with T2DM.

Many previous studies have predicted T2DM based on individuals' lipid profile (e.g., low-density lipoprotein cholesterol, highdensity lipoprotein cholesterol, fasting blood sugar, etc.) $[1,8,25]$. Because such variables are costly to measure, we instead used variables that do not require much cost to measure them (e.g., sex, age, body mass index [BMI], etc.).

Inadequate healthcare facilities in many countries, especially low-income countries, as well as the complete failure to prevent T2DM, spurred us to identify the importance of various demographic risk factors for T2DM. Artificial neural networks (ANNs) are an advanced method for estimating outcomes and prioritizing risk factors. The two medical criteria for diagnosing T2DM (fasting blood sugar and hemoglobin Alc [HbAlc]) may not be costeffective for T2DM screening on the community level.

The ANN technique is an advanced modeling technique based on brain neurons that has been widely used in recent years, and can be helpful for diagnosing, estimating, and predicting various diseases [1].

Our aim is to present a diagnostic model that can predict and determine the importance of risk factors affecting T2DM using an ANN model.

\section{MATERIALS AND METHODS}

\section{Setting and participants}

This descriptive analytical study was conducted on a sample of 234 individuals referred to a diabetes center in the city of Hamadan (in western Iran) from November 27, 2015 to March 15, 2016. The Hamadan Diabetes Risk Score study enrolled 130 normal and 130 diabetic volunteers among individuals aged 18 or more who attended the Hamadan diabetes center as a patient's companion. Of the volunteers without diabetes who were invited to participate $(\mathrm{n}=130)$, only 106 had their HbAlc measured at the laboratory, whereas all individuals with diabetes did so.

The inclusion criteria for non-diabetic subjects were age $\geq 18$ years; no mental disability; no history of type 1 diabetes, T2DM, or gestational diabetes; no current pregnancy (for female); and no current use of metformin or other glucose control drugs.

Table 1. Input and output variables for the neural network model

\begin{tabular}{|c|c|c|c|c|}
\hline Status & Attributes & Levels & Code & Descriptions \\
\hline Output & Diagnosis of T2DM (HbA1c) & $\begin{array}{l}<5.7 \% \text { : normal } \\
\geq 5.7 \% \text { : diabetic }\end{array}$ & $\begin{array}{l}0 \\
1\end{array}$ & Dichotomous (\%) \\
\hline Input & Sex & $\begin{array}{l}\text { Male } \\
\text { Female }\end{array}$ & $\begin{array}{l}0 \\
1\end{array}$ & Dichotomous \\
\hline Input & Age & - & - & Numeric (yr) \\
\hline Input & $\mathrm{BMI}^{1}$ & - & - & Numeric $\left(\mathrm{kg} / \mathrm{m}^{2}\right)$ \\
\hline Input & Hypertension ${ }^{2}$ & $\begin{array}{l}\text { Yes } \\
\text { No }\end{array}$ & $\begin{array}{l}1 \\
0\end{array}$ & Dichotomous \\
\hline Input & Walking $^{3}$ & $\begin{array}{l}<30 \\
\geq 30\end{array}$ & $\begin{array}{l}0 \\
1\end{array}$ & Dichotomous (min/d) \\
\hline Input & Sedentary time at workplace or home ${ }^{4}$ & $\begin{array}{l}\text { Sometimes } \\
\text { Often }\end{array}$ & $\begin{array}{l}0 \\
1\end{array}$ & Dichotomous \\
\hline Input & Stress & - & - & Numeric $(0-10)$ \\
\hline Input & Fruit consumption ${ }^{5}$ & Sometimes & 0 & Dichotomous \\
\hline Input & Vegetables consumption ${ }^{6}$ & Often & 1 & Dichotomous \\
\hline Input & Family history of diabetes & $\begin{array}{l}\text { Yes } \\
\text { No }\end{array}$ & $\begin{array}{l}1 \\
0\end{array}$ & Dichotomous \\
\hline Input & Smoking (cigaretts, hookah) & $\begin{array}{l}\text { Never } \\
\text { Former or current }\end{array}$ & $\begin{array}{l}0 \\
1\end{array}$ & Categorical \\
\hline Input & Waist circumference & - & - & Numeric (cm) \\
\hline
\end{tabular}

T2DM, type 2 diabetes mellitus; HbA1c, hemoglobin A1c; BMI, body mass index.

${ }^{1} \mathrm{BMI}$ calculated as weight $(\mathrm{kg}) /$ height squared $\left(\mathrm{m}^{2}\right)$.

${ }^{2}$ Participants were considered to have hypertension if they took blood pressure medication.

${ }^{3}$ Walking was collected as a dichotomous variable, walking less than $30 \mathrm{~min} / \mathrm{d}$ was denoted by "0" and walking for more than $30 \mathrm{~min} / \mathrm{d}$ was denoted as "1."

${ }^{4}$ Sedentary time was defined in terms of the amount of time (hours) a person spent sitting at the office or at home; Sedentary time less than 5 hours was denoted as "sometimes," and sedentary time for more than 5 hours was denoted as "always."

${ }^{5}$ Consumption of 0-1 servings of fruit per day was denoted as "sometimes," and consumption of $\geq 2$ servings of fruit per day was denoted as "always."

${ }^{6}$ Consumption of 0-1 cup of green vegetables per day was denoted as "sometimes," and consumption of $\geq 2$ cups per day was denoted as "always." 
Borzouei S et al. : Identifying the predictors of type 2 diabetes

The inclusion criteria for the subjects with diabetes were age $\geq 18$ years; no mental disability; the presence of T2DM without type 1 or gestational diabetes; and no current pregnancy (for female).

After obtaining informed consent, subjects were referred to the laboratory for HbA1c tests, and the diagnosis of subjects as having or not having diabetes was made based on the HbAlc results by an endocrinologist. We applied the American Diabetes Association criteria to the HbAlc results with cut-off points of less than $5.8 \%(<40 \mathrm{mmol} / \mathrm{mol})$ as normal, $5.8-6.4 \%(40-46 \mathrm{mmol} /$ $\mathrm{mol})$ as pre-diabetes, and $6.5 \%$ and more $(48 \mathrm{mmol} / \mathrm{mol})$ as indicative of T2DM [26]. For better interpretation of the results, we divided the subjects into 2 groups: normal and diabetic (i.e., prediabetes+diabetes). Informed consent was obtained from all individual participants included in the study, and the ethical committee of Hamadan University of Medical Sciences approved the study (IR.UMSHA.REC.1394.238).

\section{Statistical analysis}

Initially, using a univariate logistic regression analysis, we chose the risk factors that had a significance level of $\mathrm{p}<0.2$ (Tables 1 and 2).

In this study, we used a 3-layer ANN to model the risk factors of T2DM (Figure 1). The first layer considers input variables (i.e., neurons), the second layer considers hidden neurons, and the third considers the dichotomous output (diabetes status). The number of hidden layer neurons was determined by the rule proposed by Masters [27]. Therefore, for a 3-layer ANN with $p$ input and $q$ output neurons, the hidden layer would have $\sqrt{\left(p^{\star} q\right)}$ neurons [27].

The basic ANN was modeled as follows:

$$
y_{i}=F\left[\sum_{i=1}^{p} w_{i} x_{i}+b_{i}\right]
$$

where, $y_{i}$ denotes the output variables, $x_{i}(i=1,2, \ldots, p)$ denotes the input variables, $w_{i}(i=1,2, \ldots, p)$ denotes the optimum weights according to the input variables, and $p_{i}(i=1,2, \ldots, p)$ denotes the bias term. In this study, the sigmoid function was used as an activation function.

To avoid overfitting, and to evaluate the model's generalizability, the existing datasets were divided into 3 subsets for training (60.0\%), testing $(20.0 \%)$, and validation $(20.0 \%)$ before the modeling process began [28]. In this study, an ANN multilayer perceptron with 3 layers and the Broyden-Fletcher-Golfarb-Shanno educational algorithm were used for modeling. The reason for choosing this algorithm was its high convergence rate compared to other algorithms.

Replication experiments were used to determine the number of hidden-layer neurons, the function of the layers, and the error function, so that at each stage 100 ANNs were modeled. In order to produce an appropriate model for predicting T2DM, in the first stage, all variables were considered in the model. In the second stage, the importance of risk factors was determined using
Table 2. Risk factors used for univariate logistic regression

\begin{tabular}{|c|c|c|c|}
\hline Variables & $\begin{array}{c}\text { Normal } \\
(n=83)\end{array}$ & $\begin{array}{c}\text { T2DM } \\
(n=151)\end{array}$ & $\begin{array}{c}\text { OR } \\
(95 \% \mathrm{Cl})\end{array}$ \\
\hline Sex & & & $0.64(0.20,2.04)$ \\
\hline Male & $13(18.1)$ & $59(81.9)$ & \\
\hline Female & $70(43.2)$ & $92(56.8)$ & \\
\hline Age (yr) & $36.54 \pm 10.70$ & $53.25 \pm 11.20$ & $1.24(1.02,1.53)^{1}$ \\
\hline $\mathrm{BMI}\left(\mathrm{kg} / \mathrm{m}^{2}\right)$ & $23.10 \pm 3.59$ & $28.57 \pm 4.10$ & $1.18(0.98,1.42)$ \\
\hline Waist circumference $(\mathrm{cm})$ & $78.07 \pm 18.11$ & $102.39 \pm 10.05$ & $1.08(1.01,1.15)^{1}$ \\
\hline Stress $(0-10)$ & $5.55 \pm 2.25$ & $5.44 \pm 2.69$ & $1.42(1.13,1.79)^{1}$ \\
\hline Hypertension & & & $4.52(1.01,12.27)^{1}$ \\
\hline No & $80(50.3)$ & $79(49.7)$ & \\
\hline Yes & $3(4.0)$ & $72(96.0)$ & \\
\hline Walking (min/d) & & & $1.28(0.41,3,96)$ \\
\hline$<30$ & $36(27.3)$ & $96(72.7)$ & \\
\hline$\geq 30$ & $47(46.1)$ & $55(53.9)$ & \\
\hline \multicolumn{2}{|c|}{ Sedentary time at workplace or home } & & $6.06(2.04,8.04)^{1}$ \\
\hline Sometimes & $50(66.7)$ & $25(33.3)$ & \\
\hline Often & $33(20.8)$ & $126(79.2)$ & \\
\hline Fruit consumption & & & $0.84(0.164,4.31)$ \\
\hline Sometimes & $9(33.3)$ & $18(66.7)$ & \\
\hline Often + always & $74(35.7)$ & $133(64.3)$ & \\
\hline Vegetable consumption & & & $0.07(0.01,0.44)^{1}$ \\
\hline Sometimes & $4(6.5)$ & $58(93.5)$ & \\
\hline Often + always & $79(42.0)$ & $93(54.1)$ & \\
\hline Family history of diabetes & & & $2.94(1.08,7.83)^{1}$ \\
\hline No & $73(50.0)$ & $73(50.0)$ & \\
\hline Yes & $10(11.4)$ & $78(86.6)$ & \\
\hline \multicolumn{2}{|c|}{ Smoking (cigarettes, hookah) } & & $4.26(2.29,7.93)^{1}$ \\
\hline Never & $66(47.8)$ & $72(52.2)$ & \\
\hline Former + current & $17(7.7)$ & $79(82.3)$ & \\
\hline
\end{tabular}

Values are presented as number (\%) or mean \pm standard deviation. T2DM, type 2 diabetes mellitus; OR, odds ratio; $\mathrm{Cl}$, confidence interval; $\mathrm{BMI}$, body mass index.

${ }^{1} \mathrm{ORs}$ and $95 \% \mathrm{Cls}$ were obtained by univariate logistic regression, and significant $(p<0.2)$ risk factors.

the classification and regression tree strategy.

In the third stage, based on the backward method, less important risk factors for T2DM were eliminated. The modeling continued until the accuracy of the obtained models started to show significant differences from the first stage. Receiver operating characteristic (ROC) curves were used to compare the performance of the models. The DeLong method was used to compare the area under the ROC curve (AUC) before and after the removal of risk factors [29]. As shown in Table 1, we considered 15 features for each data sample. The diagnosis of T2DM by HbA1c was the output, and the other variables were inputs. Statistical software version R 3.2.2; neuralnet package (https://CRAN.R-project.org/package $=$ neuralnet) was used to apply neural network modeling. To register individuals' attributes, a form was used with 13 variables (Table 1$)$. 


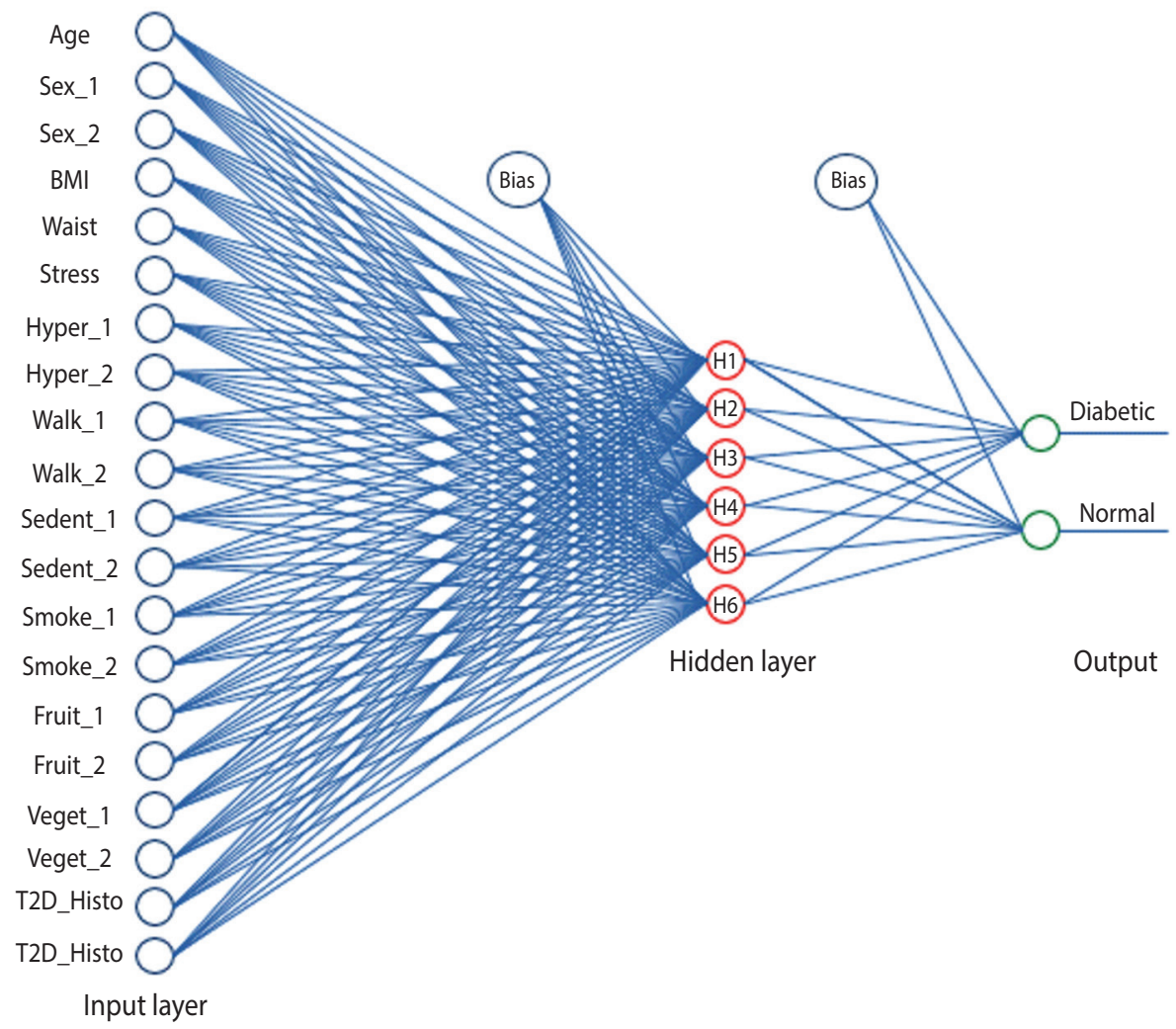

Figure 1. Artificial neural networks scheme of predictors of T2DM starting at the first step, with 20 inputs, 6 hidden layers (H1, ..., H6), and dichotomous output neurons. The encoded variables are presented in Table 1. BMI, Waist, Hyper_,Walk_, Sedent_, Veget_and T2D_Histo denote body mass index; waist circumference, hypertension status, walking time, sedentary status, vegetables consumption and family history of type 2 diabetes mellitus, respectively.

\section{RESULTS}

A total of 23 males (21.7\%) and 83 females (78.3\%), who had undiagnosed T2DM, participated in the study. The age range of the participants was $23-80$ years old. Of the participants, $12.3 \%$ had hypertension, $46.2 \%$ walked for less than $30 \mathrm{~min} / \mathrm{d}$, and $50.0 \%$ reported often leading a sedentary lifestyle at work or at home. In the present study, 21 cases (19.8\%) had a family history of T2DM, and $75(70.1 \%)$ were non-smokers.

The risk factors were then entered into the multilayer perceptron ANN model. Sensitivity, specificity, and AUC were determined. The modeling was performed 6 times, with the following results for each step.

\section{First model}

The important risk factors identified using the classification and regression tree were age (100.0\%), hypertension (57.6\%), waist circumference (55.5\%), BMI (46.9\%), a sedentary lifestyle (46.4\%), smoking (41.7\%), vegetable consumption (29.4\%), family history of T2DM (27.0\%), stress (21.3\%), walking (18.3\%), fruit consumption $(8.0 \%)$, and sex $(7.1 \%)$. The values in parentheses indicate the importance of the risk factors. Of all the risk factors, sex was the least important. Therefore, sex was eliminated from the model, and in the next step, the model was re-applied without sex.

\section{Second model}

In this step, the multilayer perceptron ANN model without the variable of sex was implemented, with 11 risk factors. The importance of the risk factors in the new model was as follows: age (100.0\%), waist circumference, (65.5\%), stress (63.3\%), BMI (63.3\%), family history of T2DM (37.6\%), vegetable consumption (31.8\%), smoking $(31.5 \%)$, a sedentary lifestyle (29.8\%), hypertension (28.6\%), walking (18.9\%), and fruit consumption (11.1\%). The DeLong method showed that the AUC of the second model did not show a significant difference $(\mathrm{p}=0.841)$ compared to the first model. Therefore, the modeling process continued.

\section{Third model}

After removing the fruit consumption variable as the least important risk factor, a multilayer perceptron ANN model with 10 variables was executed. The importance of the risk factors in the model was as follows: age (100.0\%), waist circumference (54.4\%), BMI (35.2\%), family history of T2DM (33.3\%), hypertension (28.8\%), smoking (25.1\%), stress (19.8\%), vegetable consumption 
Table 3. Results of multilayer perceptron neural network modeling

\begin{tabular}{|c|c|c|c|c|c|c|}
\hline Models & Risk factors & $\begin{array}{l}\text { Data set } \\
\text { (test) }\end{array}$ & $\begin{array}{l}\text { Sensitivity } \\
\text { (\%) }\end{array}$ & $\begin{array}{l}\text { Specificity } \\
\text { (\%) }\end{array}$ & AUC & $\begin{array}{l}\text { Accuracy } \\
\text { (\%) }\end{array}$ \\
\hline \multirow[t]{2}{*}{1} & \multirow{2}{*}{$\begin{array}{l}\text { Age, hypertension, waist circumference, BMI, sedentary lifestyle, smoking, } \\
\text { vegetable consumption, family history of T2DM, stress, walking, fruit } \\
\text { consumption, and sex }\end{array}$} & Training & 96.2 & 76.7 & 0.947 & 89.2 \\
\hline & & & 93.3 & 82.5 & 0.942 & 89.7 \\
\hline \multirow[t]{2}{*}{2} & \multirow{2}{*}{$\begin{array}{l}\text { Age, hypertension, waist circumference, BMI, sedentary lifestyle, smoking, } \\
\text { vegetable consumption, family history of T2DM, stress, walking, and fruit } \\
\text { consumption }\end{array}$} & Training & 94.0 & 79.6 & 0.920 & 90.9 \\
\hline & & & 92.2 & 75.9 & 0.931 & 86.3 \\
\hline \multirow[t]{2}{*}{3} & \multirow{2}{*}{$\begin{array}{l}\text { Age, hypertension, waist circumference, BMl, sedentary lifestyle, smoking, } \\
\text { vegetable consumption, family history of T2DM, stress, and walking }\end{array}$} & Training & 93.2 & 79.3 & 0.911 & 88.6 \\
\hline & & & 95.1 & 80.0 & 0.920 & 89.8 \\
\hline \multirow[t]{2}{*}{4} & \multirow{2}{*}{$\begin{array}{l}\text { Age, hypertension, waist circumference, BMI, sedentary lifestyle, smoking, } \\
\text { vegetable consumption, family history of T2DM, and stress }\end{array}$} & Training & 95.0 & 78.7 & 0.943 & 91.3 \\
\hline & & & 96.1 & 63.6 & 0.945 & 86.3 \\
\hline \multirow[t]{2}{*}{5} & \multirow{2}{*}{$\begin{array}{l}\text { Age, hypertension, waist circumference, BMI, smoking, vegetable con- } \\
\text { sumption, family history of T2DM, and stress }\end{array}$} & Training & 94.1 & 79.6 & 0.953 & 92.9 \\
\hline & & & 95.2 & 82.5 & 0.963 & 96.9 \\
\hline \multirow[t]{2}{*}{6} & \multirow{2}{*}{$\begin{array}{l}\text { Age, hypertension, waist circumference, BMl, smoking, family history of } \\
\text { T2DM, and stress }\end{array}$} & Training & 93.6 & 66.1 & 0.946 & 84.2 \\
\hline & & & 95.2 & 88.9 & 0.953 & 92.8 \\
\hline
\end{tabular}

AUC, area under the receiver operating characteristic curve; BMI, body mass index; T2DM, type 2 diabetes mellitus.

(18.9\%), a sedentary lifestyle (18.1\%), and walking (4.9\%). The DeLong method found that the AUC of the first and the third model did not show a significant difference $(\mathrm{p}=0.735)$. Therefore, we removed walking as the risk factor with the least importance from the model.

\section{Fourth model}

After removing the walking variable as the least important risk factor in the previous model, a multilayer perceptron model was executed with the 9 remaining risk factors. The importance of the risk factors in the model was as follows: age (100.0\%), stress (77.1\%), hypertension (69.5\%), waist circumference (57.7\%), BMI (46.6\%), vegetables (42.6\%), smoking (39.3\%), family history of T2DM (25.8\%), and a sedentary lifestyle (24.1\%). The difference in the AUC between the 2 models (i.e., the fourth model compared with the first model using the DeLong method) was not statistically significant $(p=0.588)$. Therefore, we removed a sedentary lifestyle from the fourth model and continued the modeling process without it.

\section{Fifth model}

This model included 8 risk factors. These risk factors, in order of their importance, were waist circumference (100.0\%), stress (77.2\%), age (66.8\%), BMI (63.5\%), hypertension (59.9\%), family history of T2DM (58.2\%), smoking (41.8\%), and vegetable consumption (27.1\%). The AUC of the fifth and the first models did not show a significant difference $(p=0.217)$. Therefore, we ran the multilayer perceptron ANN model again without the risk variable of vegetable consumption.

\section{Sixth model}

The sixth model included 7 risk factors: waist circumference (100.0\%), age (78.5\%), BMI (78.2\%), hypertension (69.4\%), stress (54.2\%), smoking (49.3\%), and family history of T2DM (37.2\%),

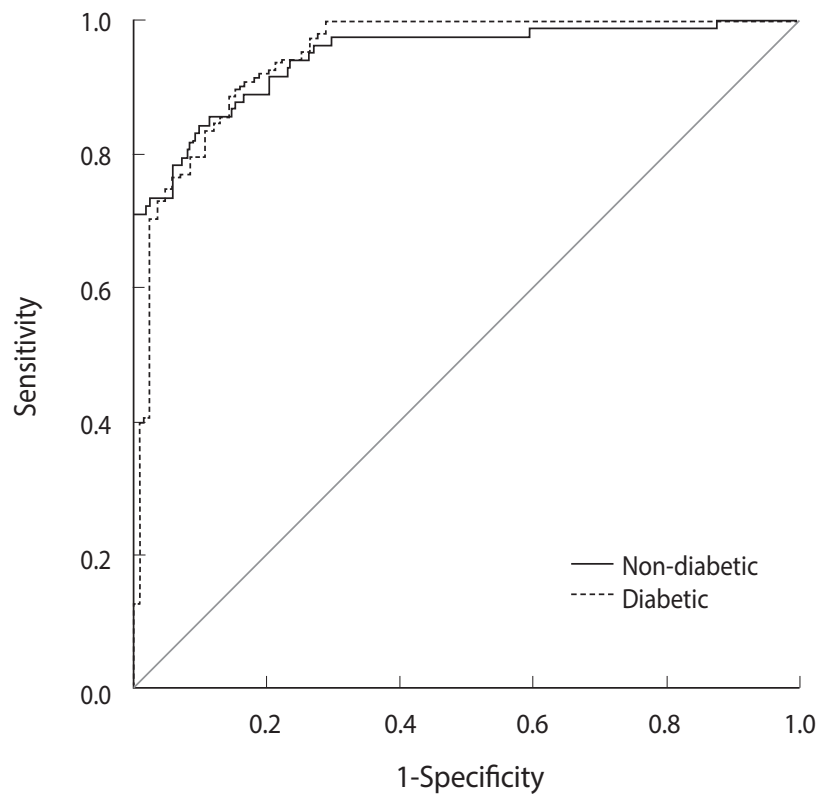

Figure 2. The area under the receiver operating characteristic curve for non-diabetic and diabetic subjects in the test and training groups based on the sixth model (final stage), containing waist circumference, age, body mass index, hypertension, stress, smoking, and family history of type 2 diabetes mellitus.

with the normalized importance rate of each risk factor shown in parentheses. The AUC of the sixth and the first models was not significantly different $(\mathrm{p}=0.206)$. The sixth ANN model was run by 5 hidden-layer neurons. The final model contained 11 input neurons and 2 output neurons.

Since the AUC of the seventh model showed a significant difference compared to that of the first model $(p=0.024)$, the modeling process was considered to be complete. The final ANN model is shown in Figure 1. The risk factors selected in the sixth model 
were identified as the best predictors of T2DM. The goodness-offit indices of models 1 to 6 are shown in Table 3. As shown in Figure 2 and Table 3, model 6 showed suitable sensitivity, specificity, and AUC values.

\section{DISCUSSION}

In this study, the diagnosis of T2DM was modeled using a multilayer perceptron ANN model. An ANN model based on a hidden layer can be used to delimit the relationships between the input variables and the output variable so that the best classification can be created. In contrast, linear models (e.g., multiple linear regression) cannot do this. The definition of such decision boundaries is possible with neural network models. Many studies $[1,8,25]$ have been conducted on the prediction of diabetes mellitus using risk factors, but most of them have considered blood lipid parameters as risk factors, although they may not be applicable in largescale screening programs for T2DM. The demographic risk factors in this study, which do not require referral to the laboratory, can be more widely used than medical risk factors $[1,8,25]$ in screening studies. This is potentially valuable because identifying people at high risk for T2DM is an important task in various communities.

Our results showed that waist circumference was very important for predicting T2DM, and was identified as the first predictor. Although the importance of waist circumference has not been confirmed in all previous studies, some studies, such as those conducted by Xu et al. [30] and Adhikary et al. [10], have reported an association between waist circumference and diabetes. Therefore, the results of this study are consistent with those of previous studies.

In the last ANN model, age was identified as the second most important factor, in accordance with previous studies [14,31]. Although age in the last ANN model ranked second, it should be noted that age had the first rank in the 5 prior ANN models. Therefore, it can be said that age is one of the strongest predictors for the diagnosis of T2DM.

Many studies [32-34] have shown that BMI may be related to T2DM, in accordance with our results. BMI was identified as the third strongest predictor for the diagnosis of T2DM in this study.

Hypertension was the fourth strongest predictor in our research, with an importance level of 69.4\%. An association between T2DM and hypertension was also reported by Wise [32], Miyakawa et al. [33], and Walther et al. [34]. Adeyemo [1] used systolic and diastolic blood pressure to predict T2DM in his research. However, a single measurement of a patient's blood pressure cannot be a reliable and valid risk factor for the diagnosis of T2DM because systolic and diastolic blood pressure readings are dependent on individual and environmental factors. We tried to measure the presence or absence of hypertension by 2 realistic questions. The first question was "Have you ever taken medication to control your blood pressure?", and the second question was "Has a doctor ever told you that you have abnormal blood pressure?"

We found a few studies $[17,18]$ that pointed out a relationship between stress and T2DM. We also measured participants' stress by a simple question with a score of 0 to 10 . The ANN results showed that stress levels were the fifth strongest predictor of a T2DM diagnosis. In other words, our study confirmed the results of previous studies $[17,18,35]$. Our results showed that stress was a more important predictor of T2DM than family history of diabetes or smoking status.

Akter et al. [36], in a systematic review and meta-analysis, showed a linear relationship between cigarette consumption and T2DM in the Japanese population, which is consistent with the outcome of our study. In this study, smoking was the sixth strongest predictor of T2DM.

The ANN model showed that the presence of diabetes among family members was a prognostic factor of T2DM. The importance of a family history of diabetes was also noted by van Zon et al. [13] and Adhikary et al. [10].

On the basis of 6 steps of modeling, we observed that risk factors such as waist, age, BMI, hypertension, stress, smoking, and family history of T2DM could play a valuable role in predicting T2DM. Therefore, we suggest that a tool should be developed based on these risk factors, in order to monitor those at high risk of T2DM and to identify undiagnosed cases of T2DM.

The risk factors in our study are cost-effective and simple to measure; virtually anyone can answer these questions in a few minutes and thereby assess his or her risk for T2DM. Another of the strengths of this study was the use of an ANN model to determine the importance of each of the risk factors. Determining the relative importance of each risk factor can be useful for health planning.

In conclusion, this study was a basic study for identifying people at high risk for T2DM. In this study, we examined demographic risk factors that do not require significant cost or time to measure in order to predict T2DM. Due to the sensitivity, specificity, and accuracy of the final model, it is suggested that these factors be used for assessing T2DM risk in screening tests.

This study had a few limitations. First, we would have liked to study more people, but due to a lack of funds, we could not increase the sample size. Second, in this study, only 1 question was used to measure stress levels, which may not be sufficiently precise. Since the participants did not want to answer a large number of questions, we had to measure stress level with a single question. Third, we measured the insufficient consumption of fruits and vegetables with 1 question. The reason for this was the reluctance of participants to respond to a large number of questions. Fourth, we evaluated walking in this study, although the results would have been more accurate if we had measured subjects' physical activity more precisely.

\section{ACKNOWLEDGEMENTS}

The participants are gratefully acknowledged for their contribution to the study. The study was funded by the Vice-Chancellor for Research and Technology of Hamadan University of Medical Sciences (grant no. 9406173162). 


\section{CONFLICT OF INTEREST}

The authors have no conflicts of interest to declare for this study.

\section{ORCID}

Ali Reza Soltanian: https://orcid.org/0000-0002-7483-3502; Shiva Borzouei: $h$ ttps://orcid.org/0000-0001-6826-9872

\section{REFERENCES}

1. Adeyemo AB, Akinwonmi AE. On the diagnosis of diabetes mellitus using artificial neural network model artificial neural network models. Afr J Comput Ict 2011;4:1-8.

2. Tripolt NJ, Narath SH, Eder M, Pieber TR, Wascher TC, Sourij H. Multiple risk factor intervention reduces carotid atherosclerosis in patients with type 2 diabetes. Cardiovasc Diabetol 2014;13:95.

3. Tuttolomondo A, Maida C, Maugeri R, Iacopino G, Pinto A. Relationship between diabetes and ischemic stroke: analysis of diabetes-related risk factors for stroke and of specific patterns of stroke associated with diabetes mellitus. J Diabetes Metab 2015;6:544.

4. World Health Organization. Prevention of blindness from diabetes mellitus: report of a WHO consultation in Geneva, Switzerland, 9-11 November 2005; 2006 [cited 2018 Mar 26]. Available from: http://apps.who.int/iris/handle/10665/43576.

5. Nasri H, Rafiean-Kopaei M. Diabetes mellitus and renal failure: prevention and managment. J Res Med Sci 2015;20:1112-1120.

6. World Health Organization. Global report on diabetes; 2016 [cited 2018 Mar 26]. Available from: http://apps.who.int/iris/bitstre am/10665/204871/1/9789241565257_eng.pdf.

7. Rawal LB, Tapp RJ, Williams ED, Chan C, Yasin S, Oldenburg B. Prevention of type 2 diabetes and its complications in developing countries: a review. Int J Behav Med 2012;19:121-133.

8. Olaniyi EO, Adnan K. Onset diabetes diagnosis using artificial neural network. Int J Sci Eng Res 2014;5:754-759.

9. Soltanian AR, Borzouei S, Afkhami-Ardekan M. Design, developing and validation a questionnaire to assess general population awareness about type II diabetes disease and its complications. Diabetes Metab Syndr 2017;11 Suppl 1:S39-S43.

10. Adhikary M, Chellaiyan VG, Chowdhury R, Daral S, Taneja N, Kumar Das T. Association of risk factors of type 2 diabetes mellitus and fasting blood glucose levels among residents of rural area of Delhi: a cross sectional study. Int J Community Med Public Health 2017;4:1005-1010.

11. Binh TQ, Nhung BT. Prevalence and risk factors of type 2 diabetes in middle-aged women in Northern Vietnam. Int J Diabetes Dev Ctries 2016;36:150-157.

12. Lee YH, Shin MH, Nam HS, Park KS, Choi SW, Ryu SY, et al. Effect of family history of diabetes on hemoglobin A1c levels among individuals with and without diabetes: the dong-gu study. Yonsei Med J 2018;59:92-100.

13. van Zon SK, Snieder H, Bültmann U, Reijneveld SA. The interaction of socioeconomic position and type 2 diabetes mellitus fam- ily history: a cross-sectional analysis of the Lifelines Cohort and Biobank Study. BMJ Open 2017;7:e015275.

14. Zhang N, Yang X, Zhu X, Zhao B, Huang T, Ji Q. Type 2 diabetes mellitus unawareness, prevalence, trends and risk factors: National Health and Nutrition Examination Survey (NHANES) 19992010. J Int Med Res 2017;45:594-609.

15. Suhail Khan M, Kumar Singh A, Bihari Gupta S, Saxena S, Maheshwari S. Assessment of risk factors of type 2 diabetes mellitus in an urban population of district bareilly. Indian J Forensic Community Med 2016;3:5-9.

16. Mi SQ, Yin P, Hu N, Li JH, Chen XR, Chen B, et al. BMI, WC, WHtR, VFI and BFI: which indictor is the most efficient screening index on type 2 diabetes in Chinese community population. Biomed Environ Sci 2013;26:485-491.

17. Hackett RA, Steptoe A. Type 2 diabetes mellitus and psychological stress: a modifiable risk factor. Nat Rev Endocrinol 2017;13: 547-560.

18. Pan KY, Xu W, Mangialasche F, Fratiglioni L, Wang HX. Workrelated psychosocial stress and the risk of type 2 diabetes in later life. J Intern Med 2017;281:601-610.

19. Bertoglia MP, Gormaz JG, Libuy M, Sanhueza D, Gajardo A, Srur A, et al. The population impact of obesity, sedentary lifestyle, and tobacco and alcohol consumption on the prevalence of type 2 diabetes: analysis of a health population survey in Chile, 2010. PLoS One 2017;12:e0178092.

20. Gao Y, Xie X, Wang SX, Li H, Tang HZ, Zhang J, et al. Effects of sedentary occupations on type 2 diabetes and hypertension in different ethnic groups in North West China. Diab Vasc Dis Res 2017;14:372-375.

21. Maddatu J, Anderson-Baucum E, Evans-Molina C. Smoking and the risk of type 2 diabetes. Transl Res 2017;184:101-107.

22. Beidokhti MN, Jäger AK. Review of antidiabetic fruits, vegetables, beverages, oils and spices commonly consumed in the diet. J Ethnopharmacol 2017;201:26-41.

23. Joseph JJ, Echouffo-Tcheugui JB, Golden SH, Chen H, Jenny NS, Carnethon MR, et al. Physical activity, sedentary behaviors and the incidence of type 2 diabetes mellitus: the Multi-Ethnic Study of Atherosclerosis (MESA). BMJ Open Diabetes Res Care 2016;4: e000185.

24. Smith AD, Crippa A, Woodcock J, Brage S. Physical activity and incident type 2 diabetes mellitus: a systematic review and doseresponse meta-analysis of prospective cohort studies. Diabetologia 2016;59:2527-2545.

25. Soltani Z, Jafarian A. A new artificial neural networks approach for diagnosing diabetes disease type II. Int J Adv Comput Sci Appl 2016;7:89-94.

26. American Diabetes Association. Diagnosis and classification of diabetes mellitus. Diabetes Care 2010;33:S62-S69.

27. Master T. Practical Neural Network Recipies in C++. 1st ed. New York: Morgan Kaufmann; 1993, p. 77-116.

28. Hastie T, Tibshirani R, Friedman J. The elements of statistical learning: data mining, inference, and prediction. 2nd ed. New York: Springer; 2009, p. 1-28. 
29. DeLong ER, DeLong DM, Clarke-Pearson DL. Comparing the areas under two or more correlated receiver operating characteristic curves: a nonparametric approach. Biometrics 1988;44:837845.

30. Xu Z, Qi X, Dahl AK, Xu W. Waist-to-height ratio is the best indicator for undiagnosed type 2 diabetes. Diabet Med 2013;30:e201e207.

31. Koelmeyer RL, Dharmage SC, English DR. Diabetes in young adult men: social and health-related correlates. BMC Public Health 2016;16:1061.

32. Wise J. High blood pressure is linked to increased risk of diabetes. BMJ 2015;351:h5167.

33. Miyakawa M, Shimizu T, Van Dat N, Thanh P, Thuy PT, Anh NT, et al. Prevalence, perception and factors associated with diabetes mellitus among the adult population in central Vietnam: a population-based, cross-sectional seroepidemiological survey. BMC Public Health 2017;17:298.

34. Walther D, Curjuric I, Dratva J, Schaffner E, Quinto C, SchmidtTrucksäss A, et al. Hypertension, diabetes and lifestyle in the longterm: results from a Swiss population-based cohort. Prev Med 2017;97:56-61.

35. Kelly SJ, Ismail M. Stress and type 2 diabetes: a review of how stress contributes to the development of type 2 diabetes. Annu Rev Public Health 2015;36:441-462.

36. Akter S, Goto A, Mizoue T. Smoking and the risk of type 2 diabetes in Japan: a systematic review and meta-analysis. J Epidemiol 2017;27:553-561. 